\title{
Validation of gamma and electron beam irradiation as alternative conservation technology for European chestnuts
}

Márcio Carocho ${ }^{\mathrm{a}}$, Amilcar L. Antonio ${ }^{\mathrm{a}, \mathrm{b}, \mathrm{c}}$, João C.M. Barreira ${ }^{\mathrm{a}, \mathrm{d}}$, Andrzej Rafalski ${ }^{\mathrm{e}}$, Albino Bento $^{a}$, Isabel C.F.R. Ferreira ${ }^{a}$ *

${ }^{a}$ Mountain Research Center (CIMO), ESA, Polytechnic Institute of Bragança, Apartado 1172, 5301-855 Bragança, Portugal

${ }^{\mathrm{b}}$ IST/ITN, Nuclear and Technologic Institute, Estrada Nacional 10, 2686-953 Sacavém, Portugal

${ }^{\mathrm{c}}$ Department of Fundamental Physics, University of Salamanca, Plaza de la Merced, 37008 Salamanca, Spain

${ }^{\mathrm{d}}$ REQUIMTE, Department of Chemical Sciences, Faculty of Pharmacy, University of Porto, Rua Jorge Viterbo Ferreira, 228, 4050-313 Porto, Portugal

${ }^{\mathrm{e}}$ Center for Radiation Research and Technology, Institute of Nuclear Chemistry and Technology, Dorodna str. 16, 03-195 Warsaw, Poland

* Author to whom correspondence should be addressed (Isabel C.F.R. Ferreira; e-mail: iferreira@ipb.pt; telephone+351-273-303219; fax +351-273-325405). 


\section{Abstract}

Chestnuts are widely consumed around the world, especially in China, which is the major producer. Portugal is the fifth biggest producer, reaching and income of $17 \mathrm{M} €$, with particular relevance for Trás-os-Montes region, which is responsible for $81 \%$ of Portuguese production. During postharvest storage, a number of pests tend to attack chestnuts, contributing to high economic losses. Since 2010, the most effective postharvest treatment, i.e. fumigation with methyl bromide, was banned in the European Union, urging producers to seek effective and reasonable alternatives. One alternative could be irradiation with gamma rays or electron beam, which is used in food commodities, legally regulated and allows outstanding results. Our research group has tested both irradiation types in chestnuts and studied the nutritional, antioxidant and other chemical parameters, obtaining promising results. Herein, we extended these studies to selected cultivars from Portugal and Italy in order to validate this technique as a viable alternative to fumigation. The selected irradiation dose ( $1 \mathrm{kGy}$ ) was chosen following previous results where it proved to be effective without causing remarkable changes in chemical or antioxidant profiles. To obtain a global knowledge about how each cultivar reacts to irradiation, principal component analysis was performed using all the measured parameters. Despite the detected differences among cultivars, which differentiated particularly Palummina and Cota, it was verified that irradiation did not cause changes in chemical and antioxidant parameters that could enable defining distinctive features among irradiated and non-irradiated chestnuts. Hence, the results herein reported might be seen as a new step toward the completion of irradiation as feasible conservation technology, independently of chestnuts origin.

Keywords: Chestnuts; European cultivars; Irradiation; Chemometric validation. 


\section{Introduction}

Among the 12 chestnut species, worldwide production is ruled by China, which contributed with $84.4 \%$ of the total production in 2010 . However, the major producers of Castanea sativa Miller, the European chestnut, are Turkey, Italy, Greece and Portugal, representing respectively $34,32,13$ and $12 \%$ of global production of this species (FAOSTAT, 2011). In Portugal, $81 \%$ of all chestnut production is located in the North region, especially in Trás-os-Montes, representing about 17 M€ of income in 2011 (INE, 2011). During the last 30 years, chestnut is gaining wider interest (Míguelez et al. 2004) promoting their export to a broader range of countries.

Chestnuts are prone to rot due to high amounts of sugars and water activity in their composition (Nazzaro et al. 2011). Furthermore, fungi like Penicillium and Aspergillus or insects like the Curcullio sikkimensis bug and the larvae of Dichocrocis punctiferalis are responsible for deterioration and destruction of chestnuts if not properly sanitized (Kwon et al. 2004; Overy et al. 2003). Until recently, the main postharvest treatment applied to chestnuts and other fruits was fumigation with various chemicals like carbon sulfide $\left(\mathrm{CS}_{2}\right)$, phosphine $\left(\mathrm{PH}_{3}\right)$ and, more commonly, methyl bromide $\left(\mathrm{CH}_{3} \mathrm{Br}\right)$. However, methyl bromide started being phased out around the world, due to heavy ozone depleting properties and toxicity to operators (UNEP, 2006), being banned within the European Union by 2010 (EU Comission Decision, 2008). Some alternatives, such as low temperature, controlled atmosphere storage and submerging in icy water for peeled chestnuts (Kwon et al. 2004) are far from ideal. Low temperature conservation is expensive, harmful to the stored goods and the adequate temperature depends on their mass (Roy et al. 2008). On the other hand, while hot water treatments waste considerable amounts of energy and might only be employed for immediate consumption, cold water 
depends on the effectiveness of anaerobic biological processes. Controlled atmosphere is a clean technology, but its application for long periods can be quite expensive (Cecchini et al. 2011).

In 1981, the Food and Agriculture Organization (FAO), International Atomic Energy Agency (IAEA) and the World Health Organization (WHO) approved food irradiation as a clean and safe technique, defining a maximum dose of $10 \mathrm{kGy}$ (Lacroix and Ouattara, 2000). In addition, food irradiation research has surpassed all other postharvest alternatives in recent decades. Chestnuts were previously irradiated at $0.25 \mathrm{kGy}$ to inhibit sprouting (Mangiacotti et al. 2009) and to prevent contamination with Curculio sikkimensis and other pests with satisfactory results, even at doses under $1 \mathrm{kGy}$ (Todoriki et al. 2006).

Our research group has thoroughly studied chestnuts in the past (Barreira et al. 2008; Barreira et al. 2009; Barreira et al. 2010; Barreira et al. 2012a), and in 2011 started researching the effects of irradiation along different storage times. The nutritional profile on irradiated chestnuts was established for both gamma and electron beam (Carocho et al. 2012a ; Fernandes et al. 2011a; Fernandes et al. 2011b), and although slight variations were induced by irradiation, the storage time caused higher changes on nutritional parameters. The nutritional value of Turkish chestnut cultivars was also studied, concluding that their behaviour towards gamma radiation was in line with the Portuguese cultivars (Barreira et al. 2012b). The antioxidant activity of chestnuts and chestnuts skin was also evaluated by our research group for both gamma and electron beam, with a slight preservation of antioxidants at specific doses, and a reduction at increasing storage times (Antonio et al. 2011; Carocho et al. 2012b). The impact of irradiation in specific groups of molecules like organic acids and triacylglycerol has also been investigated (Barreira et al. 2013; Carocho et al. 2013). Finally, in order to gather all the information regarding gamma irradiation and its influence on various parameters of chestnuts and its pests, a state of the 
art review was published (Antonio et al. 2012). Herein, the above studies were extended to Portuguese (Cota, Judia and Longal) and Italian (Palummina) cultivars, as a validation step, in order to assess the different response to both irradiation types (gamma and electron beam) at $1 \mathrm{kGy}$, the most suitable dose in our previous studies. Storage time was eliminated from this study, as its influence is by now, well known.

\section{Materials and methods}

Samples and samples irradiation

The Portuguese chestnut cultivars (Cota, Judia and Longal), belonging to Castanha da Terra Fria PDO (protected designation of origin), were obtained in October, 2012, from Trás-os-Montes orchards, while the Italian cultivar Palummina, belonging to Castagna di Montella PGI (protected geographical indication), was obtained in October, 2012, from orchards located in the Provincia di Salerno. After dividing each cultivar in two groups (with 15 units per group) the chestnuts were promptly irradiated.

Gamma irradiation took place at the Portuguese Nuclear and Technologic Institute (ITN) in Lisbon, at the Physics and Accelerator department, on the fourth level of a Cobalt- 60 Gammacell (Precisa 22, Graviner Manufacturing Company Ltd., Gosport, UK). The ${ }^{60} \mathrm{Co}$ irradiation facility consisted of a rectangular cavity with $65 \times 50 \times 20 \mathrm{~cm}(\mathrm{~h} \times \mathrm{d} \times \mathrm{w})$ surrounded with a lead protection barrier. Four ${ }^{60} \mathrm{Co}$ sources, with a total activity of 198 TBq $(5.355 \mathrm{kCi})$ in November 2012, were positioned in stainless-steel tubes located in the lateral walls of the chamber, in positions directly facing each other, about $30 \mathrm{~cm}$ above the chamber floor. The movement of the sources in the $50 \mathrm{~cm}$ long tubes was controlled by an automatic mechanism. Fricke dosimeters were placed at the corners and center of a rectangle in an area approximately equal to the sample bag. After irradiation, the absorbance of the irradiated solution was determined (Shimadzu mini UV 1240 
spectrophotometer, Kyoto, Japan) set at $305 \mathrm{~nm}$ to estimate the dose rate. The estimated dose after irradiation was $1.16 \pm 0.05 \mathrm{kGy}$.

Electron beam irradiation was performed in Warsaw, Poland, at the Institute of Nuclear Chemistry and Technology (INCT) in an electron beam irradiator of $10 \mathrm{MeV}$ of energy, a pulse duration of $5.5 \mu \mathrm{s}$, a pulse frequency of $440 \mathrm{~Hz}$, an average beam current of $1.1 \mathrm{~mA}$, a scan width of $68 \mathrm{~cm}$, a conveyer speed ranging from 20 to $100 \mathrm{~cm} / \mathrm{min}$, and a scan frequency of $5 \mathrm{~Hz}$. To estimate the dose during the irradiation process, three types of dosimeters were used: a standard dosimeter, a graphite calorimeter, and two routine Gammachrome YR and Amber Perspex dosimeters (Harwell Company, UK). The estimated dose after irradiation was $1.04 \mathrm{kGy}$, with an uncertainty of $20 \%$.

Along the text, for simplicity, we refer only the value $1 \mathrm{kGy}$ for both type of irradiation.

After irradiation, the chestnuts were milled down, lyophilized and frozen until further analyses.

Standards and reagents

Ferrous ammonium sulfate(II)hexahydrate, sodium chloride and sulfuric acid were purchased from Panreac S.A. (Barcelona, Spain) with purity PA (proanalysis), and water was treated in a Milli-Q water purification system (Millipore, model A10, MA, USA). Acetonitrile (99.9\%), n-hexane (95\%), and ethyl acetate $(99.8 \%)$ were of high-performance liquid chromatography (HPLC) grade and purchased from Lab-Scan (Lisbon, Portugal). The fatty acid methyl ester (FAME) reference standard mixture 37 (standard 47885-U) was purchased from Sigma (St. Louis, MO, USA), as well as the other individual fatty acid isomers, tocopherol, sugar and organic acid standards, trolox (6-hydroxy-2,5,7,8tetramethylchroman-2-carboxylic acid) and gallic acid. Racemic tocol $(50 \mathrm{mg} / \mathrm{mL})$ was purchased from Matreya (Pleasant Gap, PA, USA). 2,2-Diphenyl-1-picrylhydrazyl (DPPH) 
was obtained from Alfa Aesar (Ward Hill, MA, USA). All other chemicals and solvents were of analytical grade and purchased from common sources.

\section{Nutritional composition}

The samples were analysed for proximate composition (dry matter, proteins, fat, carbohydrates, and ash) using the Association of Official Analytical Chemists (AOAC) procedures (AOAC, 1995). The crude protein content of the samples was estimated by the macro- Kjeldahl method. The crude fat was determined by extracting approximately $3 \mathrm{~g}$ of powdered sample with petroleum ether, using a Soxhlet apparatus. The ash content was determined by incineration at $600 \pm 15{ }^{\circ} \mathrm{C}$. Total carbohydrates were calculated by difference. The total energy was calculated according to the following equation: energy $(\mathrm{kcal})=4($ grams of protein $)+4($ grams of carbohydrates $)+9($ grams of fat $)$.

Free sugars analysis

Free sugars were determined by high performance liquid chromatography coupled to a refraction index detector (HPLC-RI) as described previously by the authors (Barreira et al. 2010). The equipment consisted of an integrated system with a pump (Knauer, Smartline System 1000, Berlin, Germany), a degasser system (Smartline Manager 5000), an autosampler (AS-2057 Jasco, MD, USA) and a RI detector (Knauer Smartline 2300, Berlin, Germany). The data was analysed using Clarity 2.4 Software (DataApex). The chromatographic separation was achieved with a Eurospher 100-5 $\mathrm{NH}_{2}$ column $(4.6 \times 250$ $\mathrm{mm}, 5 \mathrm{~mm}$, Knauer, Berlin, Germany) operating at $30{ }^{\circ} \mathrm{C}(7971 \mathrm{R}$ Grace oven). The mobile phase was 70:30 (v/v) acetonitrile/deionized water, at a flow rate of $1 \mathrm{~mL} / \mathrm{min}$. The identification was made by comparing the relative retention times of sample peaks with 
commercially available standards. Quantification was made by the internal standard method, and the results are expressed in grams per $100 \mathrm{~g}$ of dry weight (dw).

Fatty acids analysis

Fatty acids were determined by gas-liquid chromatography coupled to a flame ionization detector (GC-FID)/capillary column. The equipment was a GC 1000 (DANI, Milan, Italy) with a split/splitless injector, a FID, and a Macherey-Nagel column $(30 \mathrm{~m} \times 0.32 \mathrm{~mm}$ inner diameter $\times 0.25 \mu \mathrm{m}$ film thickness). The oven temperature program was as follows: the initial temperature of the column was $50{ }^{\circ} \mathrm{C}$, held for $2 \mathrm{~min}$, then a $30{ }^{\circ} \mathrm{C} / \mathrm{min}$ ramp to 125 ${ }^{\circ} \mathrm{C}$, a $5{ }^{\circ} \mathrm{C} / \mathrm{min}$ ramp to $160{ }^{\circ} \mathrm{C}$, a $20^{\circ} \mathrm{C} / \mathrm{min}$ ramp to $180{ }^{\circ} \mathrm{C}$, a $3{ }^{\circ} \mathrm{C} / \mathrm{min}$ ramp to $200{ }^{\circ} \mathrm{C}$, a $20{ }^{\circ} \mathrm{C} / \mathrm{min}$ ramp to $220{ }^{\circ} \mathrm{C}$, and held for $15 \mathrm{~min}$. The carrier gas (hydrogen) flow rate was $4.0 \mathrm{~mL} / \mathrm{min}(0.61 \mathrm{bar})$, measured at $50^{\circ} \mathrm{C}$. Split injection $(1: 40)$ was carried out at $250{ }^{\circ} \mathrm{C}$. Fatty acid identification was made by comparing the relative retention times of FAME peaks from standards, as described previously by the authors (Fernandes et al. 2011a). The results were recorded and processed using CSW 1.7 software (DataApex 1.7) and expressed in relative percentage of each fatty acid.

Organic acids analysis

Organic acids were determined by high performance liquid chromatography coupled to a photodiode array detector (HPLC-PDA) as described previously by the authors (Carocho et al. 2013). The analysis was performed using a Shimadzu 20A series (Shimadzu Coperation, Kyoto, Japan). Separation was achieved on a SphereClone (Phenomenex, CA, USA) reverse phase $\mathrm{C}_{18}$ column $(5 \mu \mathrm{m}, 250 \mathrm{~mm} \times 4.6 \mathrm{~mm} \mathrm{i.d})$ thermostatted at $35^{\circ} \mathrm{C}$. The elution was performed with sulphuric acid $3.6 \mathrm{mM}$ using a flow rate of $0.8 \mathrm{~mL} / \mathrm{min}$. Detection was carried out in a PDA, using $215 \mathrm{~nm}$ and $245 \mathrm{~nm}$ (for ascorbic acid) as 
preferred wavelengths. The organic acids found were quantified by comparison of the area of their peaks recorded at $215 \mathrm{~nm}$ with calibration curves obtained from commercial standards of each compound. The results were expressed in $\mathrm{g}$ per $100 \mathrm{~g}$ of $\mathrm{dw}$.

\section{Tocopherols analysis}

Tocopherols content was determined following a procedure previously described by the authors (Fernandes et al. 2011a). The HPLC system described for sugars analysis was connected to a fluorescence detector (FP-2020; Jasco, MD, USA) programmed for excitation at $290 \mathrm{~nm}$ and emission at $330 \mathrm{~nm}$. The chromatographic separation was achieved with a Polyamide II $(250 \times 4.6 \mathrm{~mm})$ normal-phase column from YMC Waters (Dinslaken, Germany) operating at $30{ }^{\circ} \mathrm{C}$. The mobile phase used was a mixture of nhexane and ethyl acetate $(70: 30, \mathrm{v} / \mathrm{v})$ at a flow rate of $1 \mathrm{~mL} / \mathrm{min}$. The compounds were identified by chromatographic comparisons to authentic standards. Quantification was based on the fluorescence signal response, using the internal standard method. The results were expressed in $\mathrm{mg}$ per $100 \mathrm{~g}$ of $\mathrm{dw}$.

\section{Antioxidant activity evaluation}

Each sample $(1 \mathrm{~g})$ was extracted by stirring with $25 \mathrm{~mL}$ of methanol $\left(25^{\circ} \mathrm{C}\right.$ at $\left.150 \mathrm{rpm}\right)$ for $1 \mathrm{~h}$ and subsequently filtered through Whatman No. 4 paper. The residue was then extracted with $25 \mathrm{~mL}$ of methanol $\left(25^{\circ} \mathrm{C}\right.$ at $\left.150 \mathrm{rpm}\right)$ for $1 \mathrm{~h}$. The combined methanolic extracts were evaporated at $40^{\circ} \mathrm{C}$ (rotary evaporator Büchi R-210, Flawil, Switzerland) to dryness. The extracts were redissolved in methanol (final concentration $20 \mathrm{mg} / \mathrm{mL}$ ) and further diluted to different concentrations in order to obtain $\mathrm{EC}_{50}$ values (sample concentration providing $50 \%$ of antioxidant activity or 0.5 of absorbance in the reducing power assay). Trolox was used as positive control. 
DPPH radical-scavenging activity was evaluated by using an ELX800 microplate reader (Bio-Tek Instruments, Inc; VT, USA), and calculated as a percentage of DPPH discolouration using the formula: $\left[\left(\mathrm{A}_{\mathrm{DPPH}}-\mathrm{A}_{\mathrm{S}}\right) / \mathrm{A}_{\mathrm{DPPH}}\right] \times 100$, where $\mathrm{A}_{\mathrm{S}}$ is the absorbance of the solution containing the sample at $515 \mathrm{~nm}$, and $\mathrm{A}_{\mathrm{DPPH}}$ is the absorbance of the DPPH solution. Reducing power was evaluated by the Folin Ciocalteu assay and Prussian blue assay (capacity to convert $\mathrm{Fe}^{3+}$ into $\mathrm{Fe}^{2+}$, measuring the absorbance at $690 \mathrm{~nm}$ in the microplate reader mentioned above). Inhibition of $\beta$-carotene bleaching was evaluated though the $\beta$-carotene/linoleate assay; the neutralization of linoleate free radicals avoids $\beta$ carotene bleaching, which is measured by the formula: $\beta$-carotene absorbance after $2 \mathrm{~h}$ of assay/initial absorbance) $\times 100$. Lipid peroxidation inhibition in porcine (Sus scrofa) brain homogenates was evaluated by the decreasing in thiobarbituric acid reactive substances (TBARS); the colour intensity of the malondialdehyde-thiobarbituric acid (MDA-TBA) was measured by its absorbance at $532 \mathrm{~nm}$; the inhibition ratio (\%) was calculated using the following formula: $[(\mathrm{A}-\mathrm{B}) / \mathrm{A}] \times 100 \%$, where $\mathrm{A}$ and $\mathrm{B}$ were the absorbance of the control and the sample solution, respectively (Antonio et al. 2011).

\section{Statistical analysis}

All the extractions were performed in triplicate; each replicate was also measured in triplicate. Data were expressed as means \pm standard deviations.

An analysis of variance (ANOVA) with type III sums of squares was performed using the GLM (General Linear Model) procedure of the SPSS software. The dependent variables were analyzed using 2-way ANOVA, with the factors "chestnut cultivar" (CC) and "electron beam irradiation" (EB) or "gamma irradiation" (GI). When a statistically significant interaction $(\mathrm{CC} \times \mathrm{EB}$ or $\mathrm{CC} \times \mathrm{GI})$ was detected, the two factors were evaluated simultaneously by the estimated marginal means plots for all levels of each single factor. 
Alternatively, if no statistical significant interaction was verified, means were compared using Tukey's honestly significant difference (HSD) multiple comparison test.

Principal components analysis (PCA) was applied as pattern recognition unsupervised classification method. The number of dimensions to keep for data analysis was evaluated by the respective eigenvalues (which should be greater than one), by the Cronbach's alpha parameter (that must be positive) and also by the total percentage of variance (that should be as higher as possible) explained by the number of components selected. The number of dimensions considered for PCA was chosen in order to allow meaningful interpretations, and by ensuring their reliability.

All statistical tests were performed at a 5\% significance level using the SPSS software, version 18.0 (SPSS Inc).

\section{Results and discussion}

Effects on nutritional, chemical and antioxidant parameters

The effects of electron beam and gamma irradiation were previously assayed by us using different doses $(0,0.5,1,3$, and $6 \mathrm{kGy})$ as well as their interaction with storage time (Antonio et al. 2011; Barreira et al. 2013; Carocho et al. 2012a; Carocho et al. 2012b; Carocho et al. 2013; Fernandes et al. 2011a; Fernandes et al. 2011b). With no exception, storage time caused higher changes than irradiation treatment, and we were able to accurately define its true effect. Furthermore, according to the cited studies, $1 \mathrm{kGy}$ seemed to be the most suitable irradiation dose for both types of irradiation. Accordingly, we extended our research by performing a comparative study with Portuguese (Cota, Judia, Longal) and Italian (Palummina) cultivars, using fresh, gamma irradiated and electron 
beam irradiated samples, both at $1 \mathrm{kGy}$. Assaying irradiation in several cultivars is a mandatory task to validate irradiation as a conservation technology applicable to chestnuts. The interaction effect among irradiation and chestnut cultivar was also evaluated to understand if changes in chemical and antioxidant profiles may vary as function of a specific chestnut cultivar. The reported values are presented as the mean value of each irradiation among the assayed cultivars (CC: chestnut cultivar), as well as the mean value of each cultivar within each type of irradiation dose (EB: electron beam dose, GI: gamma irradiation dose). Every time the interaction among factors $(\mathrm{CC} \times \mathrm{EB}$ or $\mathrm{CC} \times \mathrm{GI})$ was significant $(p<0.05)$, acting itself as a source of variability, multiple comparison tests could not be performed. In these cases, the presented conclusions were drawn from the estimated marginal means (EMM) plots obtained in each case. Furthermore, results obtained for EB and GI were classified using a simple $t$-test for equality of means (after checking the equality of variances through a Levene's test), since there were fewer than three groups.

Table 1 shows the nutritional composition and energetic value, and also sucrose content (the only detected free sugar). The $\mathrm{CC} \times \mathrm{EB}$ interaction was significant in all cases, except dry matter, which was statistically higher in non-irradiated samples. Regarding differences among cultivars, the EMM plots (data not shown), Judia presented a lower content in fat and carbohydrates, as also a lower energetic value, while Longal showed the lowest ash content. The highest protein content was detected for Judia cultivar, although ash and sucrose were higher for Palummina and Cota, respectively. Changes caused by EB irradiation were less obvious, except for the higher content in proteins and sucrose in nonirradiated samples, which also tended to have lower carbohydrates.

The interaction $\mathrm{CC} \times \mathrm{GI}$ was also significant in all cases, not allowing any multiple comparison tests. Nevertheless, some conclusions were drawn from the correspondent 
EMM plots. Regarding differences among cultivars, Palummina presented the highest content in dry matter, fat and ash, while Judia gave the lowest values in these parameters (together with Longal, for ash content). No particular differences were found among control and gamma irradiated samples, except for a higher content in dry matter for nonirradiated samples.

In general, the obtained profiles are similar to those presented in previous studies (Carocho et al. 2012a; Fernandes et al. 2011b), despite the lower number of individual free sugars reported in this work.

The results obtained for fatty acids profile are shown in Table 2. Besides the tabled fatty acids, C6:0, C8:0, C10:0, C12:0, C14:0, C15:0, C20:2, C20:3 and C23:0 were quantified in trace $(<0.2 \%)$ amounts. The interaction among factors was significant in all cases; thereby, the following observations were drawn from the EMM plots (data not shown).

Regarding $\mathrm{CC} \times \mathrm{EB}$ interaction, Judia presented the lowest content in C17:0 (together with Palummina), C18:1 and MUFA (monounsaturated fatty acids) and the highest content in C18:2, C18:3, C22:0, C24:0 and PUFA (polyunsaturated fatty acids); Cota had the lowest contents in C18:0, C20:0, C22:0, C24:0 and SFA. On the other hand, EB did not cause noticeable effects in any of the quantified fatty acids.

In the case of $\mathrm{CC} \times \mathrm{GI}, \mathrm{CC}$ induced once again the main observed changes: Longal showed the highest content in $\mathrm{C} 16: 0$ and $\mathrm{C} 17: 0$ and the lowest content in $\mathrm{C} 16: 1, \mathrm{C} 18: 3$ and $\mathrm{C} 20: 0$; Palummina presented higher amounts of C16:1, C18:0, C18:1, C20:0 and MUFA, and lower amounts of C18:2 and PUFA; Cota had the lowest values for C18:0, C20:1 and SFA and the highest for C18:2; finally, Judia stands as having lower C18:1 and MUFA, and higher C20:1, C22:0, C24:0. The higher content in C18:3 percentage in non-irradiated samples, was the only evident change caused by GI. Despite these differences, the results 
are in agreement with previous results (Carocho et al. 2012a; Fernandes et al. 2011a; Fernandes et al. 2011b), with C16:0, C18:1 and C18:2 as the major fatty acids.

The interaction $\mathrm{CC} \times \mathrm{EB}$ had also a significant effect in the organic acids profile (except in malic acid, $p=0.142$ ) (Table 3). Concerning differences verified in CC, the most evident differences were the higher amounts of oxalic and ascorbic acids in Judia, citric acid and total organic acids for Palummina and the lower content of fumaric acid in Longal. The only differences among irradiated and non-irradiated samples were observed in ascorbic acid and fumaric acid.

Concerning GI, Judia presented the highest content in malic and ascorbic acids, while Palummina and Cota had the lowest values in ascorbic and oxalic acids, respectively. In addition, total organic acids tended to be higher in irradiated samples. The obtained profiles are also similar to previously reported results (despite being expressed in different units) assessing the effect of EB and storage time (Carocho et al. 2013).

The results for tocopherol profile (Table 4) showed also a significant interaction among factors for both types of irradiation (except $\mathrm{CC} \times \mathrm{GI}$ in $\delta$-tocopherol, $p=0.332$ ). Palummina was the cultivar with the highest content in $\alpha$-tocopherol and especially $\delta$-tocopherol, among samples used to study the effect of EB; the only evident difference among irradiated and non-irradiated samples was the higher content of $\alpha$-tocopherol in the former. In the case of GI, Palummina showed less $\gamma$-tocopherol content, while Longal tended to have higher total tocopherols; there were no differences among irradiated and nonirradiated samples (Carocho et al. 2012a; Fernandes et al. 2011a; Fernandes et al. 2011b). The assayed chestnut extracts showed antioxidant activity in all the performed assays, with $\mathrm{EC}_{50}$ results in the same range as those obtained in previous studies (Antonio et al. 2011; Carocho et al. 2012b), except for the lower $\mathrm{EC}_{50}$ values for TBARS formation inhibition. 
The interaction among factors was significant in all cases (Table 5), but the analysis of the EMM plots allowed some conclusions. In what regards EB effect, Cota extracts presented the lowest DPPH scavenging activity and reducing power (in both assays); Palummina was the best TBARS formation inhibitor and DPPH scavenger. In addition, irradiated samples showed lower ability to inhibit TBARS formation.

The samples used in GI study showed some specific trends: Cota presented once again the lowest DPPH scavenging activity, reducing power (in Folin Ciocalteau assay), TBARS formation inhibition and $\beta$-carotene bleaching inhibition. On the other hand, Palummina showed higher reducing power (assayed through Prussian blue assay) and TBARS formation inhibition, while Longal extracts stand as the strongest DPPH scavengers. There were no differences among irradiated and non-irradiated samples.

Overall, the intrinsic variability (among different cultivars) overcame differences caused by both types of irradiation. Furthermore, the interaction among irradiation and cultivar $(\mathrm{CC} \times \mathrm{EB}$ and $\mathrm{CC} \times \mathrm{GI})$ was significant in most cases, indicating that the effects caused by each irradiation type might depend on the assayed chestnut cultivars.

Principal component analysis (PCA)

After separately analysing each group of assayed parameters, PCA was applied to obtain an overview of profiling changes caused by each type of irradiation, as well as to find similarities among the assayed cultivars. The plot of component loadings for EB study was obtained with the first two dimensions (first: Cronbach's $\alpha, 0.980$; eigenvalue, 24.793; second: Cronbach's $\alpha, 0.962$; eigenvalue, 17.447), which included most variance of data (first: 46.5\%; second: 27.3\%). Objects distribution (Figure 1A) indicates clearly the separation of Palummina and Cota, while Judia and Longal revealed very similar profiles. 
Group corresponding to Palummina was more positively correlated (i.e., it presented higher values in the correspondent results) to ash, C16:0, malic, succinic and citric acids and $\delta$-tocopherol; and more negatively correlated (i.e., it presented low values in the correspondent results) to $\mathrm{C} 12: 0, \mathrm{C} 20: 1, \mathrm{C} 20: 2$ and reducing power (Prussian blue assay, PBA). Cota, in turn, presented the most positive correlations to sucrose, $\mathrm{C} 17: 0, \beta$-carotene bleaching inhibition, DPPH scavenging activity and TBARS formation inhibition; on the other hand, this group presented minimum values of C8:0, C16:1, C18:0, C20:0, SFA and reducing power (Folin Ciocalteau assay, FCA). Objects corresponding to Judia were mostly characterized by high contents in C12:0, C14:0, C15:0, C18:3, C20:2, C20:3, C23:0, C24:0, PUFA and reducing power (PBA) and low contents in carbohydrates, fat, energetic value, C18:1, MUFA and malic acid. Finally, Longal presented high positive correlations to $\mathrm{C} 16: 1, \mathrm{C} 18: 0$ and $\mathrm{C} 20: 0$ and strong negative correlations to sucrose, $\mathrm{C} 17: 0$, $\beta$-carotene bleaching inhibition, DPPH scavenging activity and TBARS formation inhibition. As it can be concluded from Figure 1B, objects correspondent to 0 and $1 \mathrm{kGy}$ were not separated at all, proving that EB did not cause remarkable changes on the chemical profiles of the assayed chestnut cultivars.

Concerning GI, objects corresponding to each chestnut cultivar were once again clearly separated. The plot was limited to the first two dimensions (first: Cronbach's $\alpha, 0.986$; eigenvalue, 28.386; second: Cronbach's $\alpha, 0.907$; eigenvalue, 8.855$)$ to allow a meaningful interpretation of the results. First two dimensions also included most of the observed variance (first: $36.9 \%$, second: $27.1 \%$ ). In this case (Figure $2 \mathbf{A}$ ), the proximity among Judia and Longal cultivars was even clearer, indicating that these cultivars have very similar chemical profiles. The group corresponding to Palummina had high positive correlations to fat, $\mathrm{C} 20: 0$, citric acid and $\delta$-tocopherol, and high negative correlations to C12:0, C24:0, ascorbic acid, malic acids and $\gamma$-tocopherol; Judia in turn, was characterized 
as having high contents in carbohydrates, C12:0, C22:0, C24:0, ascorbic acid, malic acid and $\gamma$-tocopherol and low contents of fat, C20:0 and $\delta$-tocopherol; Longal showed high positive correlations with energetic value, C15:0, C16:0, SFA and oxalic acid, and strong negative correlations with sucrose, C18:3 and reducing power (PBA). Finally, Cota was characterized by their high amounts of $\mathrm{C} 18: 3$, and high DPPH scavenging and reducing power (PBA) $\mathrm{EC}_{50}$ values; in the negative correlations branch, energetic value, $\mathrm{C} 16: 0, \mathrm{SFA}$ and reducing power (FCA) were the most correlated objects. It should be noted that a low value in reducing power measured by FCA is equivalent to a high value in reducing power assayed by PBA. Once again, it was not possible to define distinctive features (in line with EB results) for non-irradiated samples and samples irradiated with 1 kGy (Figure 2B), indicating low remarkable differences among the two groups of samples.

\section{Conclusions}

Both types of irradiation seem to constitute suitable solutions for chestnut postharvest treatments. The main differences found in chestnut chemical profiles were related to the cultivar instead of irradiation treatment, as indicated by the correlations of markers and objects in PCA. Furthermore, both kinds of irradiation seemed to attenuate chemical differences existing among Judia and Longal cultivars. This might be considered as a useful result for application of irradiation on an industrial scale because Judia and Longal are the cultivars with the highest production levels in Portuguese orchards. Moreover, the present study is an important step toward the completion of irradiation as feasible conservation technology, as confirmed by the absence of evident changes in the chemical and antioxidant profiles of chestnuts from different geographical origin.

\section{Acknowledgements}


The authors are thankful to ON.2/QREN/EU Project No.13198/2010, for financial support. A.L. Antonio and J.C.M. Barreira thank FCT, POPH-QREN, and FSE for their grants (SFRH/PROTEC/67398/2010 and SFRH/BPD/72802/2010, respectively). The authors also thank Prof. A. Chmielewski, General Director of the Institute of Nuclear Chemistry and Technology, Warsaw, Poland, for allowing electron beam irradiations.

\section{References}

Antonio, A.L., Fernandes, Â., Barreira, J.C.M., Bento, A., Botelho, M.L., \& Ferreira, I.C.F.R. (2011). Influence of gamma irradiation in the antioxidante potential of chestnuts (Castanea sativa Mill) fruits and skins. Food and Chemical Toxicology, 49, 1918-1923.

Antonio, A.L., Carocho, M., Bento, A., Quintana, B., Botelho, M.L., \& Ferreira, I.C.F.R. (2012). Effects of gamma radiation on the biological, physic-chemical, nutritional and antioxidant parameters of chestnuts - A review. Food and Chemical Toxicology, $50,3234-3242$.

AOAC. Association of Official Analytical Chemists. (1995). Official Methods of Analysis, 16th ed.; AOAC: Arlington VA.

Barreira, J.C.M., Ferreira, I.C.F.R., Oliveira, M.B.P.P., \& Pereira, J.A. (2008). Antioxidant activities of the extracts from chestnut flower, leaf, skins and fruit. Food Chemistry, $107,1106-1113$.

Barreira, J.C.M., Casal, S., Ferreira, I.C.F.R., Oliveira, M.B.P.P., \& Pereira, J.A. (2009). Nutritional, fatty acid and triacylglycerol profiles of Castanea sativa Mill. Cultivars: a compositional and chemometric approach. Journal of Agricultural and Food Chemistry, 57, 2836-2842. 
Barreira, J.C.M., Pereira, J.A., Oliveira, M.B.P.P., \& Ferreira, I.C.F.R. (2010). Sugar profiles of different chestnuts (Castanea sativa Mill.) and almond (Prunus dulcis) cultivars by HPLC-RI. Plant Foods in Human Nutrition, 65, 38-43.

Barreira, J.C.M., Casal, S., Ferreira, I.C.F.R., Peres, A.M., Pereira, J.A., \& Oliveira, M.B.P.P. (2012a). Chemical characterization of chestnut cultivars from three consecutive years: Chemometrics and contribution for authentication. Food and Chemical Toxicology, 50, 2311-2317.

Barreira, J.C.M., Antonio, A.L., Günaydi, T., Alkan, H., Bento, A., Botelho, M.L., \& Ferreira, I.C.F.R. (2012b). Chemometric characterization of gamma irradiated chestnuts from Turkey. Radiation Physics and Chemistry, 81, 1520-1524.

Barreira, J.C.M., Carocho, M., Ferreira, I.C.F.R., Antonio, A.L., Kaluska, I., Botelho, M.L., Bento, A., \& Oliveira, M.B.P.P. (2013). Effects of gamma and electron beam irradiations on the triacylglycerol profile of fresh and stored Castanea sativa Miller samples. Postharvest Biology and Technology, 81, 1-6.

Carocho, M., Barreira, J.C.M., Antonio, A.L., Bento, A., Kaluska, I., \& Ferreira, I.C.F.R. (2012a). Effects of electron-beam radiation on nutritional parameters of Portuguese chestnuts (Castanea sativa Mill.) Journal of Agricultural and Food Chemistry, 60, $7754-7760$

Carocho, M., Antonio, A.L., Barros, L., Bento, A., Botelho, M.L., Kaluska, I., \& Ferreira, I.C.F.R. (2012b). Comparative effects of gamma and electron beam irradiation on the antioxidant potential of Portuguese chestnuts (Castanea sativa Mill.). Food and Chemical Toxicology, 50, 3452-3455.

Carocho, M., Barros, L., Antonio, A.L., Barreira, J.C.M., Bento, A., Kaluska, I., \& Ferreira, I.C.F.R. (2013). Analysis of organic acids in electron beam irradiated 
chestnuts (Castanea sativa Mill.): Effects of irradiation dose and storage time. Food and Chemical Toxicology, 55, 348-352.

Cecchini, M., Contini, M., Massantini, R., Monarca, D., \& Moscetti, R. (2011). Effects of controlled atmospheres and low temperature on storability of chestnuts manually and mechanically harvested. Postharvest Biology and Technology, 61, 131-136.

EU (2008). Commission Decision of 18 September 2008. Concerning the noninclusion of Methyl Bromide in Annex I to Council Directive 91/414/EEC and the Withdrawal of Authorisations for Plant Protection Products Containing that Substance. Official Journal of the European Union, L 258/68, 26 September.

FAOSTAT (2011). Food and Agriculture Organization on the United Nations. Chestnut statistics. Available at: http://faostat3.fao.org/home/index.html\#DOWNLOAD. Accessed 15 April 2013.

Fernandes, A., Antonio, A.L., Barros, L., Barreira, J.C.M., Bento, A., Botelho, M.L., \& Ferreira, I.C.F.R. (2011a). Low dose $\gamma$-irradiation as a suitable solution for Chestnut (Castanea sativa Miller) conservation: Effects on sugars, fatty acids and tocopherols. Journal of Agricultural and Food Chemistry, 59, 10028-10033.

Fernandes, Â., Barreira, J.C.M., Antonio, A.L., Bento, A., Botelho, M.L., \& Ferreira, I.C.F.R. (2011b). Assessing the effects of gamma irradiation and storage time in energetic value and in major individual nutrients of chestnuts. Food and Chemical Toxicology, 49, 2429-2432.

INE (2011). Instituto Nacional de Estatística. Chestnuts national statistics. Available at: http://www.ine.pt/ine_novidades/Estatisticas_Agricolas_2011/index.html. Accessed 16 April 2013. 
Kwon, J., Kwon, Y., Byun, M., \& Kim, K. (2004). Competiveness of gamma irradiation with fumigation for chestnuts associated with quarantine and quality security. Radiation Physics and Chemistry, 71, 41-44.

Lacroix, M., \& Ouattara, B. (2000). Combined industrial processes with irradiation to assure innocuity and preservation of food products - A review. Food Research International, 33, 719-724.

Mangiacotti, M., Chiaravalle, A.E., Marchesani, G., Sio, A.D., Boniglia, C., Bortolini, E., \& Onori, S. (2009). Detection of irradiated chestnuts: Preliminary study using three analytical techniques. Radiation Physics and Chemistry, 78, 695-698.

Míguelez, J.D.L.M., Bernárdez, M.M., \& Queijeiro, J.M.G. (2004). Composition of varieties of chestnuts from Galicia (Spain). Food Chemistry, 84, 401-404.

Nazzaro, M., Barbarisi, C., Cara, F.L., \& Volpe, M.G. (2011). Chemical and biochemical characterization of IGP ecotype chestnuts subject to different treatments. Food Chemistry, 128, 930-936.

Overy, D.P., Seifert, K.A., Savard, M.E., \& Frisvad, J.C. (2003). Spoilage fungi and their mycotoxins in commercially marketed chestnuts. International Journal of Food Microbiology, 88, 69-77.

Roy, P., Umehara, H., Nakamura, N., Nei, D., Orikasa, T., Kitazawa, H., Okadome, H., Ishikawa, Y., Iwaki, K., Kobayashi, M., \& Shiina, T. (2008). Determination of physicochemical properties of chestnuts. Journal of Food Engineering, 87, 601-604.

Todoriki, S., Hasan, M., Miyanoshita, A., Imamura, T., \& Hayashi, T. (2006) Assessment of electron beam-induced DNA damage in larvae of chestnut weevil, Curculio sikkimensis (Heller) (Coleoptera: Curculionidae) using comet assay. Radiation Physics and Chemistry, 75, 292-296. 
UNEP, Montreal Protocol on substances that deplete the ozone layer. (2006). Report of the Methyl Bromide Technical Options Committee, 205-206, 310-313. 
Table 1. Proximate composition, sucrose content and energetic value of chestnut cultivars (CC) submitted to electron beam (EB) or gamma irradiation (GI). The results are presented as mean $\pm \mathrm{SD}^{1}$.

\begin{tabular}{|c|c|c|c|c|c|c|c|c|}
\hline & & $\begin{array}{l}\text { Dry matter } \\
(\mathrm{g} / 100 \mathrm{~g} \mathrm{fw})\end{array}$ & $\begin{array}{c}\text { Fat } \\
(\mathrm{g} / 100 \mathrm{~g} \mathrm{dw})\end{array}$ & $\begin{array}{c}\text { Proteins } \\
(\mathrm{g} / 100 \mathrm{~g} \mathrm{dw})\end{array}$ & $\begin{array}{c}\text { Ash } \\
(\mathrm{g} / 100 \mathrm{~g} \mathrm{dw})\end{array}$ & $\begin{array}{l}\text { Carbohydrates } \\
\text { (g/100 g dw) }\end{array}$ & $\begin{array}{c}\text { Sucrose } \\
(\mathrm{g} / 100 \mathrm{~g} \mathrm{dw})\end{array}$ & $\begin{array}{c}\text { Energy } \\
\text { (kcal/100 g dw) }\end{array}$ \\
\hline \multicolumn{9}{|c|}{ Electron beam irradiation } \\
\hline \multirow{5}{*}{$\mathrm{CC}$} & Cota & $54 \pm 3$ & $3.3 \pm 0.4$ & $10 \pm 1$ & $1.6 \pm 0.1$ & $85 \pm 1$ & $23 \pm 2$ & $410 \pm 2$ \\
\hline & Judia & $50 \pm 1$ & $2.0 \pm 0.5$ & $16 \pm 3$ & $1.8 \pm 0.2$ & $80 \pm 3$ & $18 \pm 1$ & $403 \pm 2$ \\
\hline & Longal & $51 \pm 2$ & $2.8 \pm 0.3$ & $12 \pm 3$ & $1.3 \pm 0.2$ & $84 \pm 3$ & $16.9 \pm 0.4$ & $409 \pm 2$ \\
\hline & Palummina & $52 \pm 8$ & $3.2 \pm 0.3$ & $9 \pm 4$ & $2.1 \pm 0.1$ & $85 \pm 4$ & $16 \pm 4$ & $408 \pm 1$ \\
\hline & $p$-value $(\mathrm{n}=18)$ & 0.143 & $<0.001$ & $<0.001$ & $<0.001$ & $<0.001$ & $<0.001$ & $<0.001$ \\
\hline \multirow{3}{*}{ EB } & $0 \mathrm{kGy}$ & $54 \pm 6 \mathrm{a}$ & $3 \pm 1$ & $13 \pm 3$ & $1.7 \pm 0.3$ & $82 \pm 2$ & $20 \pm 3$ & $407 \pm 4$ \\
\hline & $1 \mathrm{kGy}$ & $50 \pm 1 \mathrm{~b}$ & $2.9 \pm 0.3$ & $10 \pm 4$ & $1.7 \pm 0.3$ & $85 \pm 4$ & $17 \pm 3$ & $407 \pm 3$ \\
\hline & $p$-value $(\mathrm{n}=36)$ & 0.002 & 0.827 & $<0.001$ & 0.488 & $<0.001$ & $<0.001$ & 0.835 \\
\hline $\mathrm{CC} \times \mathrm{EB}$ & $p$-value $(\mathrm{n}=72)$ & 0.395 & $<0.001$ & 0.004 & $<0.001$ & 0.002 & $<0.001$ & $<0.001$ \\
\hline \multicolumn{9}{|c|}{ Gamma irradiation } \\
\hline \multirow{5}{*}{$\mathrm{CC}$} & Cota & $51 \pm 1$ & $2.4 \pm 0.2$ & $8 \pm 3$ & $1.8 \pm 0.1$ & $87 \pm 3$ & $21 \pm 3$ & $405 \pm 1$ \\
\hline & Judia & $46.8 \pm 0.5$ & $2.2 \pm 0.4$ & $11 \pm 6$ & $1.4 \pm 0.2$ & $85 \pm 6$ & $14 \pm 2$ & $405 \pm 2$ \\
\hline & Longal & $49.2 \pm 0.5$ & $2.6 \pm 0.2$ & $10 \pm 4$ & $1.3 \pm 0.3$ & $87 \pm 4$ & $15 \pm 3$ & $408 \pm 2$ \\
\hline & Palummina & $52 \pm 1$ & $2.8 \pm 0.2$ & $12 \pm 1$ & $2.0 \pm 0.1$ & $83 \pm 1$ & $20 \pm 2$ & $406 \pm 1$ \\
\hline & $p$-value $(\mathrm{n}=18)$ & $<0.001$ & $<0.001$ & 0.005 & $<0.001$ & 0.001 & $<0.001$ & $<0.001$ \\
\hline \multirow{3}{*}{ GI } & $0 \mathrm{kGy}$ & $50 \pm 2$ & $2.4 \pm 0.4$ & $10 \pm 2$ & $1.6 \pm 0.3$ & $86 \pm 3$ & $20 \pm 3$ & $406 \pm 2$ \\
\hline & $1 \mathrm{kGy}$ & $49 \pm 2$ & $2.6 \pm 0.3$ & $11 \pm 5$ & $1.7 \pm 0.3$ & $85 \pm 5$ & $17 \pm 3$ & $406 \pm 2$ \\
\hline & $p$-value $(\mathrm{n}=36)$ & $<0.001$ & $<0.001$ & 0.177 & 0.012 & 0.072 & 0.001 & 0.003 \\
\hline $\mathrm{CC} \times \mathrm{GI}$ & $p$-value $(\mathrm{n}=72)$ & $<0.001$ & $<0.001$ & 0.004 & $<0.001$ & $<0.001$ & $<0.001$ & $<0.001$ \\
\hline
\end{tabular}


Table 2. Fatty acids composition (relative percentages) of chestnut cultivars (CC) submitted to electron beam (EB) or gamma irradiation (GI). The results are presented as mean $\pm \mathrm{SD}$.

\begin{tabular}{|c|c|c|c|c|c|c|c|c|c|c|c|c|c|c|c|}
\hline & & C16:0 & $\mathrm{C} 16: 1$ & C17:0 & $\mathrm{C} 18: 0$ & C18:1 & C18:2 & $\mathrm{C} 18: 3$ & $\mathrm{C} 20: 0$ & $\mathrm{C} 20: 1$ & $\mathrm{C} 22: 0$ & $\mathrm{C} 24: 0$ & SFA & MUFA & PUFA \\
\hline \multicolumn{16}{|c|}{ Electron beam irradiation } \\
\hline \multirow{5}{*}{$\mathrm{CC}$} & Cota & $13 \pm 1$ & $0.28 \pm 0.04$ & $0.19 \pm 0.01$ & $0.83 \pm 0.03$ & $36 \pm 2$ & $43 \pm 1$ & $5 \pm 1$ & $0.27 \pm 0.02$ & $0.6 \pm 0.1$ & $0.21 \pm 0.04$ & $0.14 \pm 0.02$ & $15 \pm 1$ & $37 \pm 2$ & $49 \pm 2$ \\
\hline & Judia & $13 \pm 1$ & $0.38 \pm 0.05$ & $0.16 \pm 0.01$ & $0.95 \pm 0.03$ & $26 \pm 1$ & $48 \pm 1$ & $9 \pm 1$ & $0.32 \pm 0.02$ & $0.7 \pm 0.1$ & $0.35 \pm 0.04$ & $0.25 \pm 0.04$ & $16 \pm 1$ & $27 \pm 1$ & $57 \pm 1$ \\
\hline & Longal & $13.7 \pm 0.5$ & $0.5 \pm 0.2$ & $0.19 \pm 0.02$ & $1.1 \pm 0.3$ & $31 \pm 2$ & $45 \pm 1$ & $7 \pm 1$ & $0.4 \pm 0.1$ & $0.5 \pm 0.1$ & $0.33 \pm 0.05$ & $0.20 \pm 0.03$ & $16 \pm 1$ & $32 \pm 2$ & $52 \pm 2$ \\
\hline & Palummina & $13.8 \pm 0.2$ & $0.4 \pm 0.1$ & $0.17 \pm 0.01$ & $0.9 \pm 0.1$ & $34 \pm 4$ & $43 \pm 3$ & $5 \pm 1$ & $0.31 \pm 0.04$ & $0.46 \pm 0.03$ & $0.24 \pm 0.03$ & $0.16 \pm 0.01$ & $15.9 \pm 0.3$ & $35 \pm 4$ & $49 \pm 4$ \\
\hline & $p$-value $(\mathrm{n}=18)$ & $<0.001$ & $<0.001$ & $<0.001$ & $<0.001$ & $<0.001$ & $<0.001$ & $<0.001$ & $<0.001$ & $<0.001$ & $<0.001$ & $<0.001$ & $<0.001$ & $<0.001$ & $<0.001$ \\
\hline \multirow{3}{*}{$\mathrm{EB}$} & 0 kGy & $13 \pm 1$ & $0.4 \pm 0.1$ & $0.18 \pm 0.01$ & $1.0 \pm 0.2$ & $33 \pm 5$ & $44 \pm 3$ & $6 \pm 2$ & $0.3 \pm 0.1$ & $0.6 \pm 0.1$ & $0.3 \pm 0.1$ & $0.2 \pm 0.1$ & $16 \pm 1$ & $34 \pm 5$ & $50 \pm 5$ \\
\hline & $1 \mathrm{kGy}$ & $13.6 \pm 0.5$ & $0.3 \pm 0.1$ & $0.18 \pm 0.02$ & $0.9 \pm 0.1$ & $31 \pm 3$ & $46 \pm 2$ & $7 \pm 1$ & $0.30 \pm 0.04$ & $0.6 \pm 0.1$ & $0.27 \pm 0.04$ & $0.18 \pm 0.03$ & $16 \pm 1$ & $32 \pm 3$ & $53 \pm 2$ \\
\hline & $p$-value $(\mathrm{n}=36)$ & $<0.001$ & $<0.001$ & 0.280 & $<0.001$ & $<0.001$ & $<0.001$ & $<0.001$ & $<0.001$ & $<0.001$ & 0.002 & $<0.001$ & 0.126 & $<0.001$ & $<0.001$ \\
\hline $\mathrm{CC} \times \mathrm{EB}$ & $p$-value $(\mathrm{n}=72)$ & $<0.001$ & $<0.001$ & $<0.001$ & $<0.001$ & $<0.001$ & $<0.001$ & $<0.001$ & $<0.001$ & $<0.001$ & $<0.001$ & $<0.001$ & $<0.001$ & $<0.001$ & $<0.001$ \\
\hline \multicolumn{16}{|c|}{ Gamma irradiation } \\
\hline \multirow{4}{*}{$\mathrm{CC}$} & Cota & $14 \pm 1$ & $0.4 \pm 0.1$ & $0.19 \pm 0.02$ & $0.85 \pm 0.05$ & $30 \pm 2$ & $46 \pm 1 \mathrm{a}$ & $7 \pm 1$ & $0.35 \pm 0.02$ & $0.51 \pm 0.05$ & $0.25 \pm 0.01$ & $0.16 \pm 0.01$ & $16 \pm 1$ & $31 \pm 2$ & $53 \pm 1$ \\
\hline & Longal & $15.7 \pm 0.5$ & $0.30 \pm 0.02$ & $0.24 \pm 0.03$ & $0.97 \pm 0.04$ & $32 \pm 1$ & $44 \pm 1 \mathrm{~b}$ & $5.4 \pm 0.5$ & $0.31 \pm 0.01$ & $0.62 \pm 0.02$ & $0.25 \pm 0.02$ & $0.16 \pm 0.03$ & $18 \pm 1$ & $33 \pm 1$ & $49 \pm 1$ \\
\hline & Palummina & $15 \pm 1$ & $0.6 \pm 0.1$ & $0.15 \pm 0.01$ & $1.1 \pm 0.1$ & $34 \pm 1$ & $41 \pm 3 \mathrm{c}$ & $6.7 \pm 0.5$ & $0.45 \pm 0.04$ & $0.52 \pm 0.05$ & $0.27 \pm 0.02$ & $0.16 \pm 0.02$ & $18 \pm 1$ & $35 \pm 1$ & $48 \pm 1$ \\
\hline & $p$-value $(\mathrm{n}=18)$ & $<0.001$ & $<0.001$ & $<0.001$ & $<0.001$ & $<0.001$ & $<0.001$ & $<0.001$ & $<0.001$ & $<0.001$ & $<0.001$ & $<0.001$ & $<0.001$ & $<0.001$ & $<0.001$ \\
\hline \multirow{3}{*}{ GI } & $0 \mathrm{kGy}$ & $15 \pm 1$ & $0.4 \pm 0.1$ & $0.18 \pm 0.02$ & $1.0 \pm 0.1$ & $30 \pm 3$ & $44 \pm 2 \mathrm{a}$ & $7 \pm 1$ & $0.37 \pm 0.05$ & $0.6 \pm 0.1$ & $0.27 \pm 0.03$ & $0.16 \pm 0.03$ & $17 \pm 1$ & $31 \pm 3$ & $51 \pm 3$ \\
\hline & $1 \mathrm{kGy}$ & $15 \pm 1$ & $0.4 \pm 0.1$ & $0.19 \pm 0.05$ & $0.9 \pm 0.1$ & $32 \pm 2$ & $44 \pm 2 \mathrm{a}$ & $6 \pm 1$ & $0.35 \pm 0.05$ & $0.6 \pm 0.1$ & $0.27 \pm 0.03$ & $0.17 \pm 0.02$ & $17 \pm 1$ & $33 \pm 2$ & $50 \pm 2$ \\
\hline & $p$-value $(\mathrm{n}=36)$ & $<0.001$ & $<0.001$ & $<0.001$ & $<0.001$ & $<0.001$ & $<0.001$ & $<0.001$ & 0.001 & $<0.001$ & 0.725 & $<0.001$ & $<0.001$ & $<0.001$ & $<0.001$ \\
\hline $\mathrm{CC} \times \mathrm{GI}$ & $p$-value $(\mathrm{n}=72)$ & $<0.001$ & $<0.001$ & $<0.001$ & $<0.001$ & $<0.001$ & 0.689 & $<0.001$ & 0.012 & $<0.001$ & 0.001 & $<0.001$ & $<0.001$ & $<0.001$ & $<0.001$ \\
\hline
\end{tabular}


Table 3. Organic acids composition (g $100 \mathrm{~g} / \mathrm{dw}$ ) of chestnut cultivars (CC) submitted to electron beam (EB) or gamma irradiation (GI). The results are presented as mean $\pm \mathrm{SD}^{1}$.

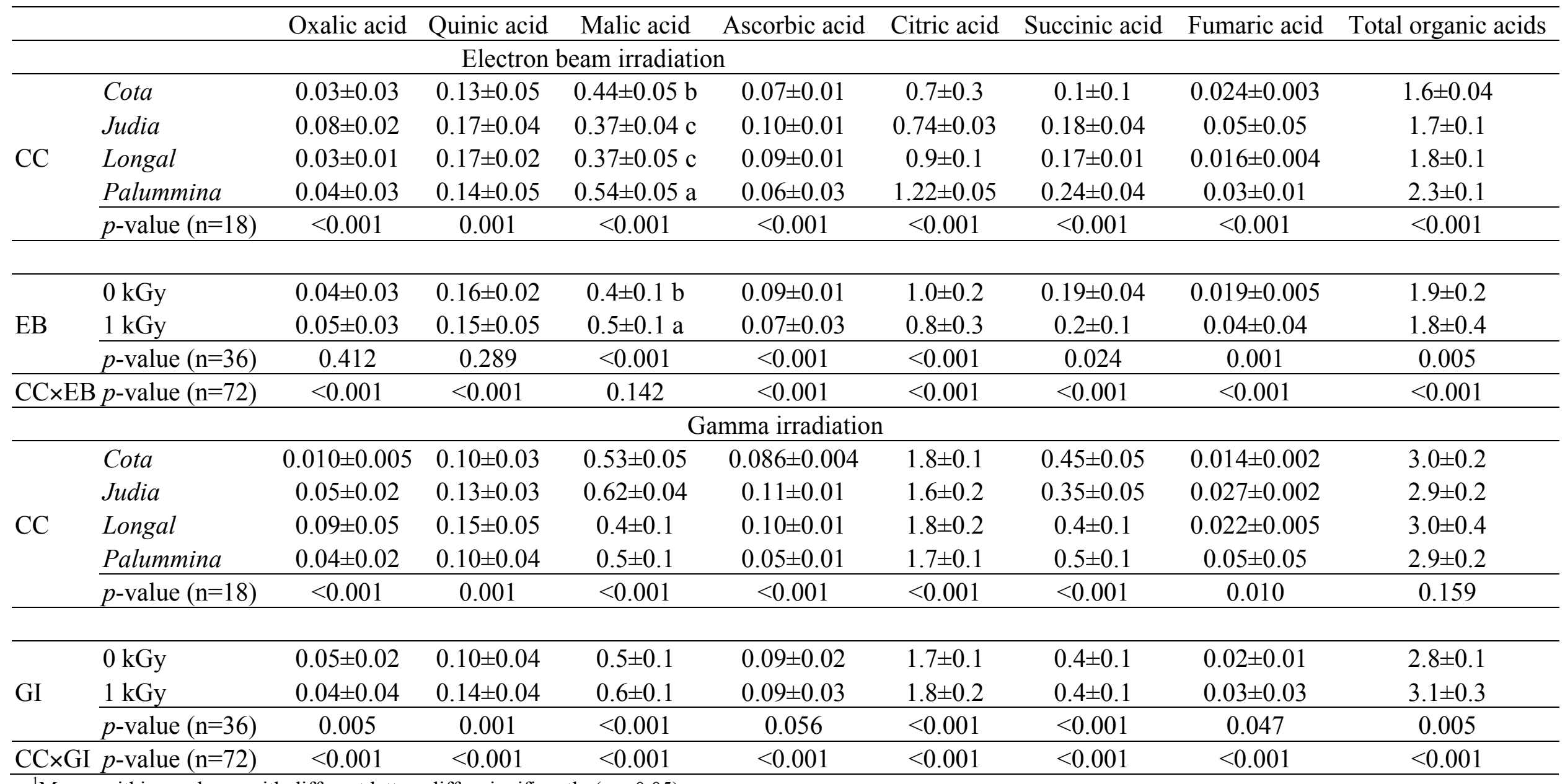

\footnotetext{
${ }^{1}$ Means within a column with different letters differ significantly $(p<0.05)$.
} 
Table 4. Tocopherols composition ( $\mu \mathrm{g} 100 \mathrm{~g} / \mathrm{dw}$ ) of chestnut cultivars (CC) submitted to electron beam (EB) or gamma irradiation (GI). The results are presented as mean $\pm \mathrm{SD}^{1}$.

\begin{tabular}{|c|c|c|c|c|c|}
\hline & & $\alpha$-Tocopherol & $\gamma$-Tocopherol & $\delta$-Tocopherol & Total tocopherols \\
\hline \multicolumn{6}{|c|}{ Electron beam irradiation } \\
\hline \multirow{5}{*}{$\mathrm{CC}$} & Cota & $1.1 \pm 0.5$ & $764 \pm 78$ & $15 \pm 3$ & $780 \pm 79$ \\
\hline & Judia & $1.2 \pm 0.5$ & $672 \pm 93$ & $11 \pm 01$ & $683 \pm 93$ \\
\hline & Longal & $0.8 \pm 0.4$ & $797 \pm 134$ & $19 \pm 2$ & $817 \pm 134$ \\
\hline & Palummina & $1.5 \pm 0.5$ & $778 \pm 136$ & $150 \pm 24$ & $930 \pm 119$ \\
\hline & $p$-value $(\mathrm{n}=18)$ & $<0.001$ & $<0.001$ & $<0.001$ & $<0.001$ \\
\hline \multirow{3}{*}{ EB } & $0 \mathrm{kGy}$ & $0.7 \pm 0.1$ & $685 \pm 16$ & $54 \pm 70$ & $739 \pm 61$ \\
\hline & $1 \mathrm{kGy}$ & $1.5 \pm 0.5$ & $821 \pm 141$ & $43 \pm 49$ & $865 \pm 164$ \\
\hline & $p$-value $(\mathrm{n}=36)$ & $<0.001$ & $<0.001$ & $<0.001$ & $<0.001$ \\
\hline \multicolumn{2}{|c|}{$\mathrm{CC} \times \mathrm{EB} p$-value $(\mathrm{n}=72)$} & $<0.001$ & $<0.001$ & $<0.001$ & $<0.001$ \\
\hline \multirow{5}{*}{$\mathrm{CC}$} & Cota & $2 \pm 2$ & $867 \pm 75$ & $18 \pm 3 \mathrm{~b}$ & $887 \pm 75$ \\
\hline & Judia & $2 \pm 1$ & $858 \pm 56$ & $15 \pm 5 \mathrm{~b}$ & $875 \pm 57$ \\
\hline & Longal & $1.1 \pm 0.3$ & $915 \pm 74$ & $23 \pm 3 \mathrm{~b}$ & $939 \pm 76$ \\
\hline & Palummina & $1.6 \pm 0.2$ & $722 \pm 140$ & $109 \pm 51 \mathrm{a}$ & $833 \pm 135$ \\
\hline & $p$-value $(\mathrm{n}=18)$ & $<0.001$ & $<0.001$ & $<0.001$ & 0.003 \\
\hline \multirow{3}{*}{ GI } & $0 \mathrm{kGy}$ & $2 \pm 1$ & $808 \pm 107$ & $45 \pm 45$ & $854 \pm 69$ \\
\hline & $1 \mathrm{kGy}$ & $2 \pm 1$ & $873 \pm 117$ & $40 \pm 40$ & $913 \pm 111$ \\
\hline & $p$-value $(\mathrm{n}=36)$ & 0.787 & 0.001 & 0.239 & 0.004 \\
\hline \multicolumn{2}{|c|}{$\mathrm{CC} \times$ GI $p$-value $(\mathrm{n}=72)$} & $<0.001$ & 0.008 & 0.332 & 0.028 \\
\hline
\end{tabular}

${ }^{1}$ Means within a column with different letters differ significantly $(p<0.05)$. Results are reported as mean value of each irradiation dose (EB or GI) over the different chestnuts cultivars (CC) as well as mean value of all CC within each EB or GI. Therefore, SD reflects values in those samples (under different EB/GI or CC). 
Table 5. Antioxidant properties obtained for the extracts of chestnut cultivars (CC) submitted to electron beam (EB) or gamma irradiation (GI). The results are presented as mean $\pm \mathrm{SD}$. Values are presented as $\mathrm{EC}_{50}$ values $(\mathrm{mg} / \mathrm{mL})$ for all assays except FolinCiocalteau, expressed as $\mathrm{mg} \mathrm{GAE/g} \mathrm{extract.}$

\begin{tabular}{|c|c|c|c|c|c|c|}
\hline & & \multirow[b]{2}{*}{$\begin{array}{c}\text { DPPH scavenging } \\
\text { activity }\end{array}$} & \multicolumn{2}{|c|}{ Reducing power } & \multicolumn{2}{|c|}{ Lipid peroxidation inhibition } \\
\hline & & & $\begin{array}{c}\text { Prussian } \\
\text { blue assay }\end{array}$ & $\begin{array}{c}\text { Folin Ciocalteu } \\
\text { assay }\end{array}$ & $\begin{array}{c}\text { TBARS formation } \\
\text { inhibition }\end{array}$ & $\begin{array}{c}\beta \text {-Carotene bleaching } \\
\text { inhibition }\end{array}$ \\
\hline \multicolumn{7}{|c|}{ Electron beam irradiation } \\
\hline \multirow{5}{*}{$\mathrm{CC}$} & Cota & $22 \pm 2$ & $1.7 \pm 0.1$ & $3.4 \pm 0.2$ & $1.2 \pm 0.1$ & $3 \pm 1$ \\
\hline & Judia & $12 \pm 2$ & $2.5 \pm 0.3$ & $9 \pm 1$ & $0.6 \pm 0.1$ & $1.8 \pm 0.1$ \\
\hline & Longal & $9.2 \pm 0.2$ & $2.5 \pm 0.2$ & $8 \pm 1$ & $0.63 \pm 0.03$ & $2.6 \pm 0.4$ \\
\hline & Palummina & $11 \pm 3$ & $0.9 \pm 0.3$ & $10 \pm 1$ & $0.53 \pm 0.03$ & $2 \pm 1$ \\
\hline & $p$-value $(\mathrm{n}=18)$ & $<0.001$ & $<0.001$ & $<0.001$ & $<0.001$ & $<0.001$ \\
\hline \multirow{3}{*}{ EB } & $0 \mathrm{kGy}$ & $13 \pm 4$ & $1.8 \pm 0.4$ & $8 \pm 3$ & $0.7 \pm 0.2$ & $199 \pm 42$ \\
\hline & $1 \mathrm{kGy}$ & $13 \pm 6$ & $2 \pm 1$ & $7 \pm 3$ & $0.7 \pm 0.3$ & $3 \pm 1$ \\
\hline & $p$-value $(\mathrm{n}=36)$ & 0.646 & $<0.001$ & $<0.001$ & 0.692 & $<0.001$ \\
\hline $\mathrm{CC} \times \mathrm{EB}$ & $p$-value $(\mathrm{n}=72)$ & $<0.001$ & $<0.001$ & $<0.001$ & $<0.001$ & $<0.001$ \\
\hline \multicolumn{7}{|c|}{ Gamma irradiation } \\
\hline \multirow{5}{*}{$\mathrm{CC}$} & Cota & $10.9 \pm 0.4$ & $2.63 \pm 0.04$ & $4.6 \pm 0.3$ & $1.1 \pm 0.2$ & $1.2 \pm 0.1$ \\
\hline & Judia & $7 \pm 1$ & $2.0 \pm 0.4$ & $10 \pm 3$ & $1.2 \pm 0.2$ & $0.9 \pm 0.4$ \\
\hline & Longal & $7 \pm 1$ & $1.6 \pm 0.2$ & $9 \pm 1$ & $0.8 \pm 0.4$ & $2 \pm 1$ \\
\hline & Palummina & $5.4 \pm 0.5$ & $2.1 \pm 0.3$ & $13 \pm 1$ & $0.5 \pm 0.1$ & $1.8 \pm 0.1$ \\
\hline & $p$-value $(\mathrm{n}=18)$ & $<0.001$ & $<0.001$ & $<0.001$ & $<0.001$ & $<0.001$ \\
\hline \multirow{3}{*}{ GI } & $0 \mathrm{kGy}$ & $8 \pm 2$ & $2.0 \pm 0.4$ & $9 \pm 3$ & $0.7 \pm 0.3$ & $2 \pm 1$ \\
\hline & $1 \mathrm{kGy}$ & $8 \pm 2$ & $2.1 \pm 0.4$ & $8 \pm 3$ & $1.1 \pm 0.3$ & $1.2 \pm 0.4$ \\
\hline & $p$-value $(\mathrm{n}=36)$ & $<0.001$ & $<0.001$ & $<0.001$ & $<0.001$ & $<0.001$ \\
\hline $\mathrm{CC} \times \mathrm{GI}$ & $p$-value $(\mathrm{n}=72)$ & $<0.001$ & $<0.001$ & $<0.001$ & $<0.001$ & $<0.001$ \\
\hline
\end{tabular}




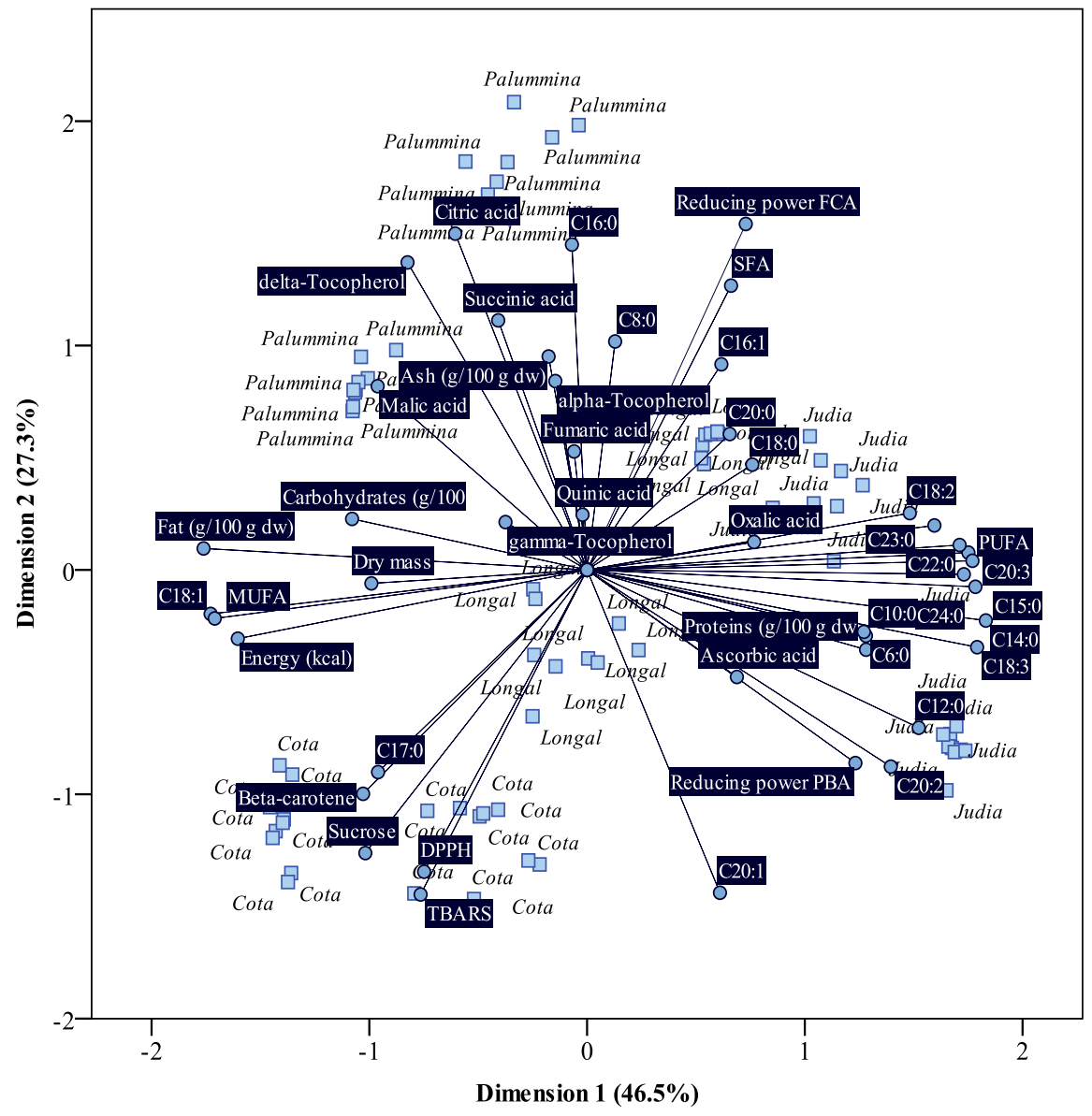

A

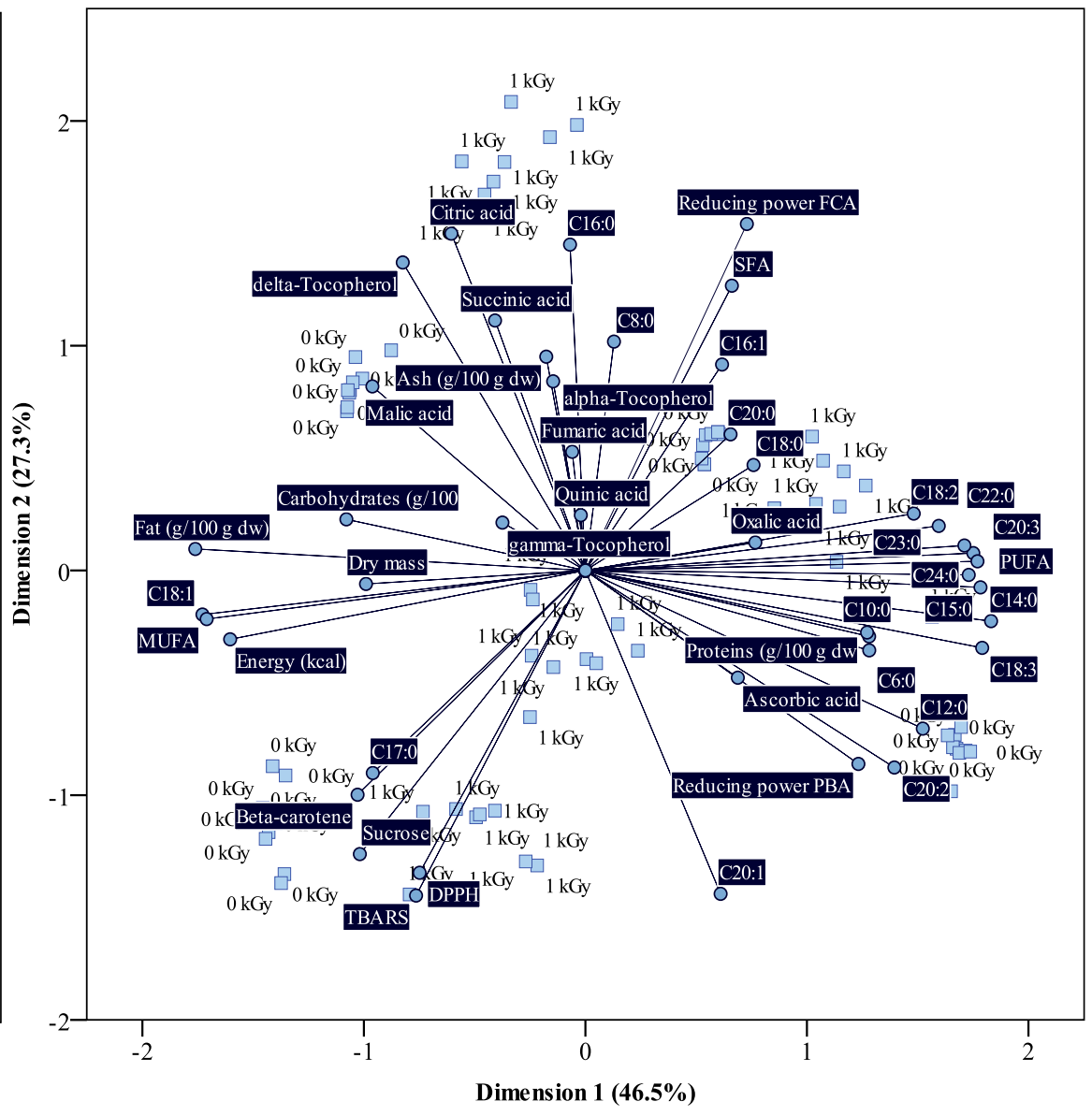

B

Figure 1. Biplot of objects (A- chestnut cultivars; B- irradiation doses) and component loadings (evaluated parameters) for electron beam study. 


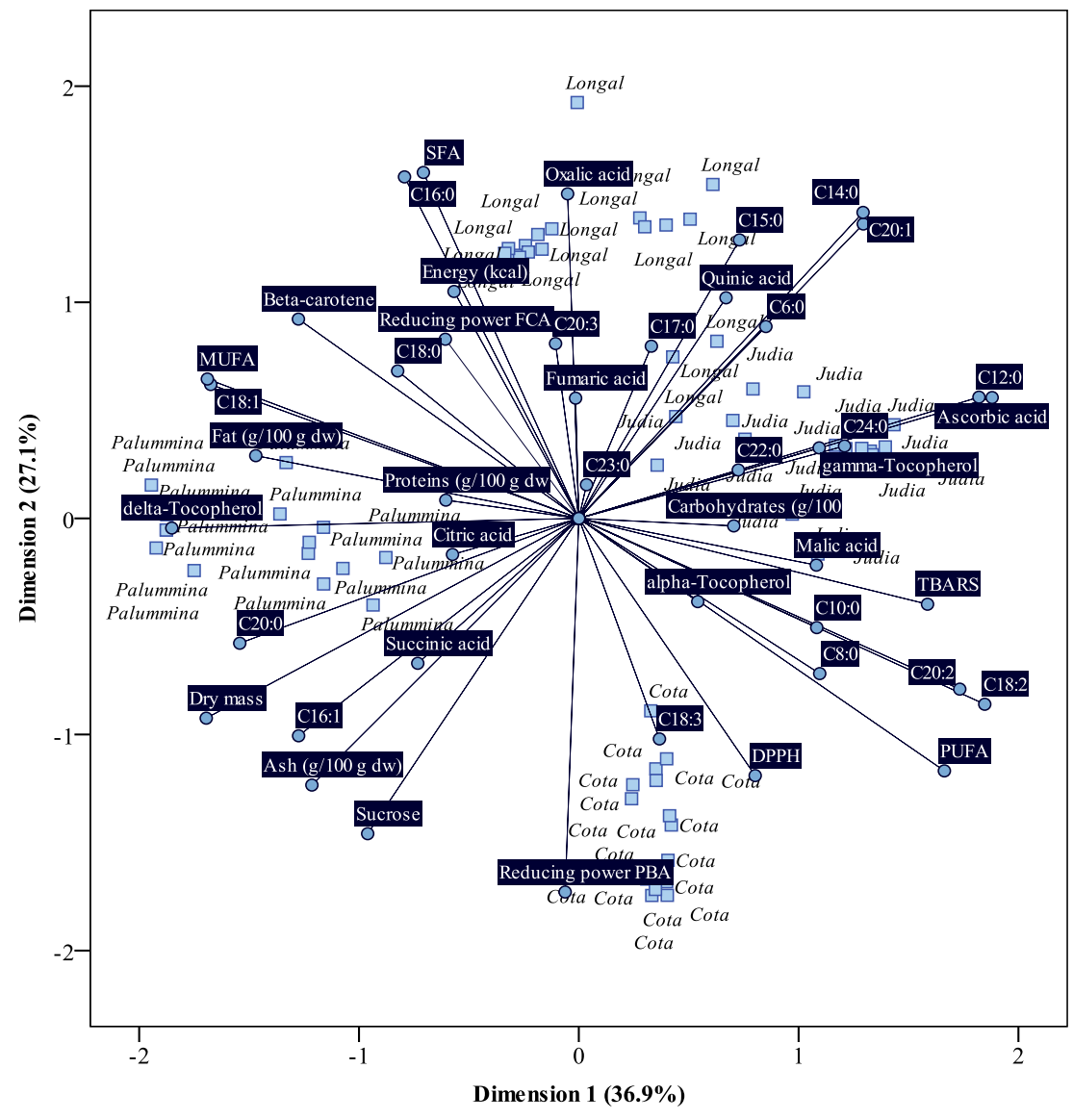

A

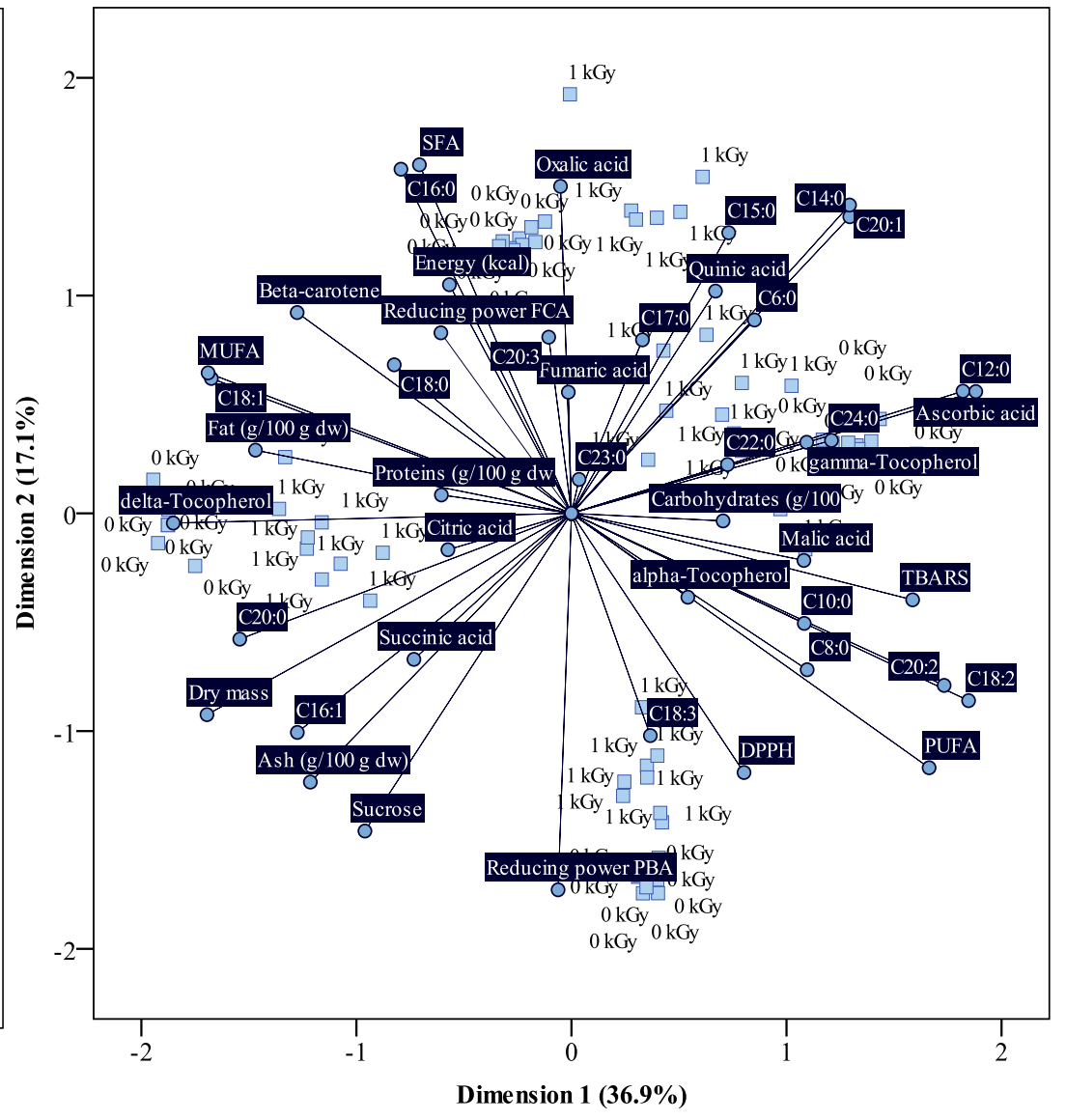

B

Figure 2. Biplot of objects (A- chestnut cultivars; B- irradiation doses) and component loadings (evaluated parameters) for gamma irradiation study. 